\title{
Introduction: Imagining Subject
}

Situated precariously between Taiwan and China, the Matsu archipelago is even more diminutive than the Trobriand Islands. From the islands, which belong to Taiwan, one can see cargo vessels sailing along the Chinese coastline during the day and watch the city lights glimmering across the water after dark-China is but a stone's throw away. In fact, to go from Beigan, one of the northern islands, to the mainland city of Huangqi, takes only half an hour by ferry, while a trip to Taiwan involves traversing the tempestuous "dark trench" (hei shuigou) of the Taiwan Strait. Taking nine hours over rough seas, the journey can sometimes seem longer than flying across the Pacific to American shores.

At first glance, one's eyes are immediately drawn to the stone houses that dot the islands' mountainous landscape. Unlike the residential courtyards found in southern Fujian province, most of these homes are stand-alone two-story structures, tucked attractively into the folds of the mountains. Their unique name, huang ngiang nah (F. foreign shelters), points to the fact that they display some Western architectural elements (Fig. 0.1). It is said that they were designed both as a response to and an improvement on the Western architecture built in China after the signing of the 1842 Treaty of Nanking and the opening up of the Fuzhou harbors (Zheng 2003). Walking through the villages, one occasionally still comes across slogans attached to the exterior walls- "Take back the mainland" (guangfu dalu); "Eliminate the traitors Zhu De and Mao Zedong" (xiaomie zhu mao hanjian); and "Cooperation between soldiers and civilians" (junmin yijia) — a reminder of the archipelago's history as a military frontline. After refurbishment done as part of village preservation projects, 


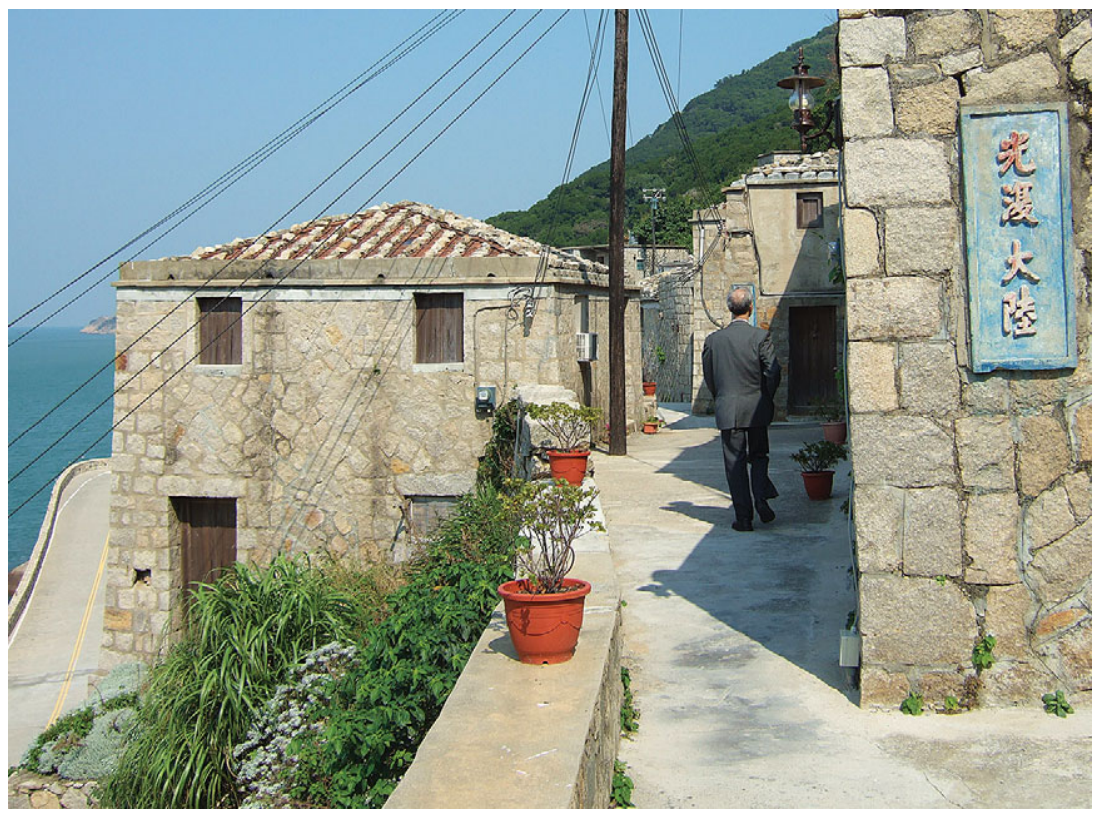

Fig. 0.1 Strolling along the alleyways of Matsu

many of these stone dwellings have been turned into lodgings for visitors. These former "foreign shelters" have taken up fashionable Europeansounding names such as "Mediterranean Villa," "Santorini Inn," or "Aegean Sea of Love Bed \& Breakfast." Walking in the circuitous alleyways is like entering the galleries of history.

Towering above the simple stone houses on the peak of a southern island stands a finely wrought, recently finished giant statue of the Goddess Mazu. Since the islands are named after her, in recent years many places have developed according to the catchphrase "Goddess Mazu in Matsu." This enormous image was built in imitation of the Mazu statue on Meizhou Island, China. Now, she not only looks out over the vast ocean, summoning the fishermen home, but the angle of the statue has been carefully adjusted so that the Goddess faces her birthplace in China: Meizhou Island in Putian. The direction of her gaze reveals the ardent hope and imagination entertained by Matsu residents today of reconnecting with Taiwan and China. 


\section{Imagination, Media, and Contemporary Society}

Social imaginary is the way in which the members of a community imagine their existence. It forms the common understanding of how to carry out the collective practices that constitute social life (Taylor 2004: 23-4). In contemporary times, imagination has taken on increasing significance. Whether in anthropology or in cultural studies, imaginary has tended to take on weight comparable to culture, belief, or meaning (Strauss 2006: 322), if not replace them. Why is this the case?

It is undeniable that the flourishing of modern media technologies has created new possibilities for imagination to develop. But the uncertainty that people confront in the contemporary world also impels various kinds of imagination to appear, as is seen widely in many fields. ${ }^{1}$ Arjun Appadurai (1996) in the early 1990s initiated a series of papers exploring the importance of modern imagination. He posits that the world we inhabit today is characterized by a new role in social life for imagination, which is a constitutive feature of modern subjectivity (31). Since the 1980 s, the rising popularity of electronic media, as well as mass migration, has loosened the intimate bonds between people and territories in traditional society: the world has undergone a process of deterritorialization and re-territorialization (49; see also Gupta and Ferguson 1997: 50). In other words, electronic media marks the coming of a new era: it intervenes in public life and reshapes society by virtue of its wide reach and speed of transmission. So, indeed, does mass migration. Although mobility has always existed in history, when modern migration was accompanied by the rapid flows of mass-mediated messages, images, and sensations, cultural reproduction could not continue as before. Imagination has thus acquired a new power in contemporary society (53).

Appadurai, however, does not deny the importance of imagination in traditional societies; rather, he discusses how mass media brought about new kinds of imagination and results: imagination has become a part of everyday life, a way for individuals to negotiate with the wider, globalized world, and to constitute modern self and subjectivity (3). By juxtaposing previous works with contemporary global transformations, Appadurai contributed important insights to many later studies. Below, I scrutinize 
the important issues relating to imagination in the literature both before and after him, since the varied workings of imagination in society is one of the central concerns of this book.

Humans are born with an innate ability to imagine, but in reality only some imaginations are able to develop from one or more individuals into the collective and become shared social imaginaries, that is, common images or representations held by most people that influence society significantly. The role of the mediating mechanism in this process is pivotal. Benedict Anderson (1991[1983]), for instance, in his seminal book Imagined Community, depicts how print-capitalism brought about a fundamental transformation in how people "think" the world (22). Taking novels and newspapers as examples, he explicates how these media create homogeneous, empty time and comparable social space (24). These temporal and spatial constructions generate a commonality among people and lay the basis for nationalism.

The significance of collective imagining in the formation of modern Europe is explored more systematically by Charles Taylor (2004). He argues that revolutionary social imaginaries usually come from elites' or prophets' original theories of moral order, which over the long march of history gradually infiltrate into ordinary people's minds. In Europe, it was through three kinds of social forms-market economy, public sphere, and self-governed people-that social imaginary was finally transfigured. It is worth noting that Taylor greatly expands the discussion of social imaginary from print media to broader social institutions. But his analysis, as Crapanzano (2004: 7) suggests, does not delve into "how this infiltration works, nor does he discuss the potential contradictions, tensions, and disjunctions in it." It is not surprising that subsequent research focused on "the technologies of imagination" (Sneath, Holbraad, and Pedersen 2006: 11), that is, the concrete processes by which imaginative effects are engendered. In ensuing works, the function of medium has also received more attention. Belting (2011[2001]: 20) calls it "an act of animation," triggering the transference of the individual imagination into a collective perception, as an appropriate medium can open the door to knowledge, enabling the personal mental image to be apprehended and become the collective "picture" in the public space (15). Meyer (2015) develops this idea in her study of Ghana, discussing 
how movies function as a "synchronizing actor" to transform individual imaginations into a shared collective imaginary.

In the contemporary era, however, we increasingly engage with, and live in, multiple imagined worlds. Unconstrained by territorial bounds, our connections with others are far more complex and fragmentary than before. Many new elements, such as ethnicity, media, technology, finance, and ideology, have arisen to generate larger imaginaries, or "scapes," as Appadurai (1996: 33) termed them. These scapes are usually unfixed, irregular, and able to contest with each other or even subvert the official regulations. To sum up, the imagined worlds in contemporary time are spaces of contestation in continual flux (4); their relations can no longer be explicated in terms of the traditional political economy or the central/peripheral dichotomy. How should we understand the emergence and interplay of these different imaginaries?

\section{The Invisible Subject}

Although many of the aforementioned scholars have raised important points about social imaginary, most of their works are premised on the collective or social without delving into individual imaginations (Crapazano 2004: 1; Rapport 2015: 8; Robbins 2010: 306), or more precisely, the imagining subjects. What their works crucially miss is the active agent who initiates the imaginings. I consider that the imagining subject has been rendered invisible largely for two distinct reasons.

First is a tendency among scholars to adopt a top-down perspective. Anderson, for example, explores the formation of an imagined community in terms of print capitalism, yet his work rarely treats the imagining subject and the process of imagination (Axel 2003: 121). Similarly, Appadurai's research emphasizes how people in the present age can use electronic media to achieve previously unimagined imaginaries. But he mainly focuses on the influence of media and technology without considering the individual imagination. This is shown in how he distinguishes two forms of imagination (1996: 7): fantasy, which is private, personal, and often emancipatory; and collective imagination, which is the force behind the formation of neighborhoods, societies, and nationstates, and which could become the fuel for social action. It is clear that 
he places greater importance on the latter. Although Taylor touches upon individuals - particularly elites - and how their thinking spreads to the larger community via economics, politics, and the public sphere, he rarely explicates how exactly they communicate with each other, and the process by which ideas are negotiated and reconciled.

The second reason that the imagining subject is invisible is probably historical, and specific to the society under study. In a given society or historical era, there may be a larger institution existing that prevents us from readily seeing the individual imagination. The Matsu archipelago, the fieldsite of this book, is a case in point of how imagination can be obscured for various distinct reasons. Until the eighteenth century, the Matsu Islands were considered by the central Chinese government as a "forbidden outpost," to which officials could exile people at will. The inhabitants consisted of a largely transient population who survived by fishing. Social relations on the islands were based on kinship and ties to their original hometowns in the coastal regions of southeast China (see Chapter 1). Relying on the mainland to fulfill many of their basic needs, the residents' lives were only partially conducted on the islands. Some particularly daring individuals rose to become feared pirates who dominated the sea, but their reigns mostly proved to be short-lived. During the early period, life on the islands was transitory and intermittent. Given the extremely limited data, it is all the more difficult for us to know how individuals' imaginations developed during that time.

The conflict between the Communist Party and the Nationalist Party in China, as well as the US-Soviet Cold War, drastically changed the fate of Matsu. Overnight, Matsu was sealed off from Taiwan and China and turned into a frontline in Taiwan's defensive strategy against China. The archipelago was ruled by the army for more than forty years (1949-92). In order to transform the barren fishing islands into a solid base for the army, the military government during this period carried out large-scale modernization projects, including improving infrastructure, building schools, and even implementing a guaranteed admission program to send Matsu students to Taiwan for advanced education. All of this brought about tremendous changes in the previously desolate islands. However, the dark side of this seemingly bright picture is that local 
fishermen were greatly restricted in their access to the water and their movements at sea. The fishing economy - the lifeblood of the islandsgradually waned. More than two-thirds of the inhabitants left the islands in the 1970s for jobs in Taiwan. Although some commerce based on army supplies did emerge, and the government also offered some jobs, most of these vocations were at the bottom rungs of the military-ruled society; that the government exerted strict control on the bodies and thoughts of locals goes without saying.

In the face of military rule, the individual imagination was largely concealed and expressed privately. For example, Matsu fishermen knew of places on the sea which were beyond military detection, and where they could snatch brief moments of enjoyment outside state control to meet with fishermen friends from China, but those interludes were mostly secret (see Chapter 3). The islanders also elaborated their gambling habits into a kind of imaginative practice in which they could mock, evade, or even contend with the state; but their gambling had to be clandestinely conducted in out-of-the-way places, such as the dark corners of offices, storehouses, tunnels, or even graveyards, as Chapter 4 will show.

Undoubtedly, the pervasive suppression encouraged many Matsu people, especially the early wave of youngsters who were sent to Taiwan to study and who absorbed ideas of liberty there, to rise up in tandem with the Taiwan democratic movement and take to the streets to demand freedom. After two major demonstrations and peaceful sit-ins to protest the military rule, marital law was lifted in 1992, and Matsu finally won its freedom. Subsequent improvements in aviation and naval transport brought Matsu people in touch with the wider world, and the islands were no longer isolated. The advent of internet technologies offered more possibilities for imagination to develop. When the new social media spread to the whole archipelago in the form of a popular website, Matsu Online, which was set up in 2001, the residents were afforded greater freedom to express their opinions, connect with each other in the virtual world, and enthusiastically engage in public issues. The individual imagination has gained a larger space to express itself and explore in the online world. 


\section{Subjectification and the Ethical Imagination}

It is important to take a closer look at the question of how long-oppressed and confined individuals could become imagining subjects. How does their subjectivity take shape, and what is the process of their subjectification? Many anthropological studies of subjectivity have looked at these issues; I benefit particularly from the works of Henrietta Moore (1994, 2007,2011 ) who notes that subjectivity and subjectification have not been defined in a rigorous way in anthropology. Subjectivity in general denotes "inner states or perceptions that engage with affect, cognition, morality and agency" (Biehl et al. 2007: 1; Ortner 2005: 31; see also Holland and Leander 2004: 127; Luhrmann 2006: 345). Of these, agency - that is, how people act in the world-is underscored by most of the scholars.

Among these broad definitions, Moore (2011: 72) identifies two perspectives. The first one is cultural, proposed by Ortner (2005) who reinterprets Geertz and highlights the aspects of how "the cultural and social formations shape, organize, and provoke ... modes of affect and thought" (2005: 31). This standpoint is clearly based on culturally constituted feelings, desires and intentions (34). The second perspective is experiential, postulated by Kleinman and Fitz-Henry (2007). They discuss the variability, heterogeneity, and contingency of subjectivities taking shape in the realm of experiences that are usually intersubjective, involving practices, negotiations, and contestations when interacting with others. Experience for them is thus the medium within which collective and subjective processes fuse and condition each other. Although they do not deny that subjectivity is also constrained by culture, symbols, and meanings as Ortner posits, they argue that experience can reconfigure and repattern cultural contents (53).

Moore, however, indicates that experience in this approach is formulated in a rather loose way: what it entails is not really explored. Intersubjectivity and the process of subjectification are also undertheorized. Above all, these discussions are limited to the frame of subjects, without exploring "the specific grounds for transformations in subjectivities and in the forms and mechanism of subjection" (73). The factors which affect on individuals are usually generalized as "exterior" 
elements: "interior" self and "exterior" influences are separated. Even when they interact, the consequence is usually termed as "hybridity" of modernization or globalization.

Moore suggests that this interior/exterior dichotomy has to be transcended to reach an understanding of how the process of subjectification, or becoming a subject, evolves. In her earlier works (1994: 55; 2007: 17), she differentiated self and subject, showing that the self is constituted by multiple subject positions. Her later work (2011) develops how various kinds of mediums, or "the forms of the possible" (18) in her own words, can reshape self. She takes new media as an example to show how it can magnify "interior" meanings and feelings, supplementing and extending individual sensations and emotions (Moore 2011: 116), and engendering new agency and social connections. This is the process of subjectification which not only creates new subjects, but also reconstitutes self-other relations. She thus advocates that we should break the interior/exterior division and see new media technologies as second nature to humans, with which individuals are able to create new worlds and become "relational" subjects (78). For her, modern computer-mediated technologies are only one of the possible mediums. People also deploy objects (Latour 1993, 2005) and art forms (Gell 1998) to create new social ties and cultural contents. As she writes:

Humans use objects and technologies to extend our reach across space and time, to create new forms of self, of social relations and social ontologies. ... New technologies enhance our capacities for virtuality and for making social relations. They not only make new ways of seeing possible, but they are productive of new relays of affect and intensity which in turn produces new cultural forms and cultural capacities. (Moore 2011: 127)

This way of discussing self is undoubtedly much indebted to Foucault's concept of "the ethical subject" (1985; 1998), which concerns the mode of subjectification, technologies of the self, and the mode of being that the subject aspires to achieve. However, she proceeds to elaborate it into the idea of "the ethical imagination" (Moore 2011: 15-21; Long and Moore 2013) in which she delves further into selfother relations, in particular, the forms and means through which individuals imagine relationships to themselves and to others, and the unconscious affects, emotions, and fantasies which are thereby generated. This 
analytical framework is helpful in investigating the emergence of imagining subjects after the demilitarization of Matsu, the major concern of this book. Going further, I will discuss how their rich imaginations, as developed through different media technologies, enhance our understanding of the formation of the social imaginary. The online creation of wartime memory, discussed in Chapter 6, provides a vital clue to this process.

\section{From Deserted Islands to an Enchanted Place}

The weblog series The Wartime Childhood of Leimengdi appeared on Matsu Online, a popular website reporting on Matsu. It began in 2005 and was published over the course of three years. The posts were copiously illustrated by Chen Tianshun, a Taiwan-based emigrant from Matsu, and the text was written by his Taiwanese wife, Xia Shuhua. Their collaborative project was widely read and much beloved during its serialization; when later published in book form, residents voted to designate it a "Book of Matsu." The series records the childhood memories of Chen Tianshun, who grew up in Matsu during military rule. The rich culture and ecology of the islands marked him profoundly, but the trauma of military rule also left permanent psychological scars. Owing to the decline of the fishing economy, his entire family left the islands when he was fifteen. He attended a vocational school of art and design in Taiwan and worked there as an illustrator. He and his family lived a relatively secluded life in Taipei, and for nearly three decades he never set foot on Matsu. He hardly spoke about his childhood even to his wife, and his past was seemingly a painful secret that he tried to forget or hide.

Only when Matsu Online appeared as a forum for him to unburden himself by exercising his talent, was he moved to draw upon his deeply buried memories. Throughout the process, he was buoyed by his wife's engaging writing and an outpouring of emotional support from netizens. The co-active structure of internet technology (Web 2.0) quickly engendered intersubjective communication and mutual empathy between him and a growing group of netizens (Dijck 2007; Cappelletto 2005a, 2005b). A shared image of wartime Matsu emerged, and it consoled his displaced 
heart. By the relay of feelings and affects stimulated by drawing for the public on the internet, the interstices of the inner and the outer, the individual and the social were crossed out. Chen was finally able to surmount the sufferings of his childhood and reposition himself between Matsu and Taiwan. He was invited back to Matsu, where he gave talks and taught drawing to school children. After setting foot once again on Matsu, he was even stirred to fight for the ethical value of the unmourned and unremembered dead who had lost their lives because of military rule. One could say that the creation of the weblog series was Chen Tianshun's process of subjectification: his values, morals, and emotions were reconstituted, and he discovered new momentum to move forward.

This process of subjectification is not unique to Chen Tianshun but can also be seen in the middle-aged generation of Matsu residents, in particular those who went to work in Taiwan or were sent there to study by the guaranteed admission program during the military rule, and subsequently returned home to work. The challenges that Matsu faced after the ending of military rule were considerable. When Matsu suddenly stopped being a frontline in 1992, uncertainty plagued the islands. After more than forty years of military rule, Matsu's economy had already shifted from fishing to a system centered around providing goods and services for the army. As tensions between the two sides of the Taiwan Strait diminished, the number of garrisons stationed on the islands greatly decreased. With military demand sharply down and with the economy dwindling year after year, prospects for Matsu looked bleak. Although its designation as a waypoint between China and Taiwan in 2001 temporarily alleviated anxiety, Matsu was even more marginalized after direct transportation links were established in 2008, bypassing the islands. What could Matsu do to avoid returning to its state a century ago as a group of desolate, isolated islands? A disturbed and restless atmosphere was growing.

At that point, a series of plans for the development of the islands- or put more accurately, different imaginaries to reposition Matsu vis-à-vis China and Taiwan, Asia, or even the world-were proposed to explore possibilities for the future of Matsu. The driving force behind the scenes was the "imagining subjects," namely, the persons who had been sent to Taiwan to study by the guaranteed admission program and who came back to work. 
They had grown up in Matsu and experienced the hardships and traumas of military rule. After studying and working in Taiwan, they realigned their warzone experiences with their newly acquired knowledge and proposed a profusion of new blueprints for the islands.

I emphasize that these persons were not just "thinking subjects engaged in dialogue with a variety of broader intellectual debates and projects" (Miyazaki 2013: 6, italic original), but imagining subjects imbued with strong feelings and attachments to their hometown and the desire to find a way out for their suffering land. Their repositioning of Matsu took on particular significance for those who had lived through the wartime period: as a frontline of hostilities, Matsu was seen as "the Fortress of the Taiwan Strait" (taihai baolei) and a "springboard for anticommunism" (fangong tiaoban), its value defined solely by its military strategic importance. The process of repositioning and reimagining Matsu after the lifting of martial law became a method for a long-oppressed populace to rediscover itself, and to find a new identity and a way of existing meaningfully in the world. In other words, the pursuit of these new imaginaries is thus not only motivated by politico-economic factors; more correctly, it is a series of self-explorations, the process of subjectification: the people who were traumatized by the army reconstitute themselves by reconstructing the place in which they live. With this in mind, we can understand why the islanders, in particular the middle-aged generation, during this moment were all engaged in a continuous creation of new imaginaries for Matsu.

\section{Imagining Subject Unveiled}

This book brings imagining subjects to the fore and examines the transformation of individual imaginations into social imaginaries from three perspectives.

\section{Imagining Subjects as Individuals or Cohorts}

First, the imagining subjects can be individuals. Every person has the capacity to imagine, to develop and refine imaginations over time into one's own values and beliefs. Personal ability and life experience are thus important for my analysis of the formation of individual imagination. As those with unique historical experiences often become "key social actors" 
(Boyer and Lomnitz 2005: 113) in moments of rapid change, their struggles, affects, and the new imaginaries they devised are discussed in detail in this book.

Importantly, the imagining subject can also be a social cohort. Having gone through similar life experiences, people of the same generation, gender, or social category are more likely to form common imaginaries. As mentioned above, the middle-aged generation that went to Taiwan to receive advanced education or to work was inspired by the new thoughts and trends they encountered there. When the military government retreated from Matsu, they took official positions in the local government, gaining a chance to develop their individual thoughts into social imaginaries. However, that is not to suggest that they could dominate or unilaterally determine the formation of social imaginary. Rather, I wish to highlight how this generation has been constantly challenged by, and has had to negotiate with, those who have very different historical experiences and social lives, and therefore, social imaginaries. This includes the older generation of fishermen who struggled for their livelihoods on the sea, and the young post-martial-law members of society who grew up after military rule and have no experience of living in wartime. From this perspective, this book differs from previous studies in being concerned with different imagining subjects; their varied senses of self, belonging, and imaginations of the future; and the processes by which they negotiate with each other.

Apart from these generational gaps, differences in gender are also important. The traditional fishing economy of Matsu favored men over women, whose lives were centered on their families and who had little opportunity for higher education. It was not easy for them, nor was it even their major concern to come up with sweeping images of the islands' future. However, their struggle between the competing pull of family and career can be seen as a prism that reflects the challenges that contemporary Matsu society confronts today.

\section{Subjectification through New Technologies of Imagination}

Second, this book discusses how imagining subjects deploy different kinds of mediating mechanisms to infiltrate their imaginations into the society. Drawing on Moore (2011), I analyze how people use mediating 
technologies to enhance and magnify their individual imaginations, expanding social relations and creating new cultural identifications. I define mediating technologies broadly, including general media as well as all kinds of materials, events, and practices (Mazzarella 2004), which engage not only thought and reflection but also affect and fantasy. In the twenty-first century, these technologies recompose religious symbols, practices, and modes of belonging in terms of economic, performative, or scientific forces, and radically extend these traditional elements for a new era (Stolow 2005: 123).

From Chapter 5 to 10 , I discuss how imagining subjects have employed different as well as new technologies to create, negotiate, and win support for different imaginaries: some used the internet to assert their freedom of expression when the islands were just emerging from military control; some introduced new cultural projects, attempting to remake Matsu as an "Eastern Fujian Culture Village" (Mindong wenhua cun). Some adopted and revised traditional Taiwanese-style pilgrimages and material practices to expand the cultural and social space of Matsu and connect it with Taiwan and China, joining the "Cross-Strait Economic Zone" (Haixi jingji qu). Others invited an American casino capitalist to bring the gaming industry to Matsu, hoping to transform the islands into an "Asian Mediterranean" (Yazhou dizhonghai).

Many of these projects did not achieve their goals. However, more important than their success or failure, these plans should be considered as both self-realizations of the imagining subjects and persistent collective efforts to "remain in presence- that is, to exist" (Latour 1993: 129). The islanders, in Latour's words, "do not land on an essence, but on a process, on a movement, a passage"; they attempt to reckon with their state of indeterminacy - a precarious existence without the promise of stability as described by Tsing (2015: 20 ).

\section{Social Imaginaries as Reconfigurations of the Politico-Economy}

Finally, this book posits that all imaginative practices have to contend with the realities of global power dispositions. Now that Matsu is no longer a frontline, its residents have been consecutively designing novel ways forward for the islands. We might say that imagination was given an unprecedented chance to develop during this time of drastic change: from the community project to build an "Eastern Fujian Culture Village," to 
the idea of using pilgrimages to join China's "Cross-Strait Economic Zone," to bringing in gaming to create an "Asian Mediterranean." All these were technologies of "social envisioning" (Peter 1997: 97) for the people who were facing an uncertain future, allowing them to seek out new potentialities by relocating Matsu between the two sides of the Taiwan Strait as well as in the world.

It is undeniable that there are layered grids of politico-economic power relations behind these imaginary creations of place identity (Gupta and Ferguson 1997). In the case of Matsu, it is the political wrestling between the two sides of the Strait and also the expansion of capitalist forces in China and its zoning strategies (Ong 2006: 104-5) which have continually pushed the new envisionings of the de-militarized islands. Many previous studies have already made the connection between capitalism and imagination, and have generally considered the former to give rise to the latter (Anderson 1991[1983]; Harvey 1990). ${ }^{2}$ For contemporary anthropologists, cultural imaginations are not just reflections or consequences of capitalism or neoliberalism, but people's imaginary reconfigurations of economic and social conditions (Kapferer, Eriksen, and Telle 2009). These imaginations contain people's experience and criticism of capitalism, as well as their aspirations for the future (Comaroff and Comaroff 1999, 2000, 2002; Weiss 2009). ${ }^{3}$

In Matsu, each time a new imaginary was introduced, the relations between the islands and the wider world were rescaled (Hatfield 2019: 268; Tsing 2005: 58). These imaginings were the means by which the local aspiring subjects resituated their home amid a new hierarchy of political and economic power distributions, as well as responding to a particular historical moment. These responses, moreover, were not just imitations of the way that Matsu subjects envisaged the world, but rather imaginative reconfigurations of their place within the new regional and global order. These imaginaries both mediated between people and their local society, and also acted as intermediaries between their lived place and world at large.

\section{In-betweenness, Hope, and the Future}

Still, we must press further and ask: are these imaginaries actually capable of producing the outcomes that aspiring subjects hope for? The answer is: not always. In Matsu, the formation of community through 
temple building is a success. In other cases, the results are equivocal. For example, the "Eastern Fujian Culture Village" project did manage to restore some scenic sites of the village, but because it failed to attract widespread participation from the population, interest gradually faded. The use of pilgrimages and other religious material practices to connect Matsu with Taiwan and China also proved not fully workable after a few attempts because of the rapidly changing politico-economic dynamics and infrastructure developments in China. The proposal to create an "Asian Mediterranean" by bringing the gaming industry to Matsu did not receive much support from the central governments on either side of the Strait, and it remains unresolved today.

The significance of imagination, however, resides not in its immediate or achievable effects, but in its capacity to create open-ended ways of "knowing in being" (Ingold 2013: 747). Imagination is characterized by anachronistic and magical qualities (Belting 2011[2001]: 36) that are related to the real but distinct from it. The appearance of a particular type of imaginary is usually a response to a historical era, so it can be merely a temporary answer that fades over time. But it can also incite more possibilities for the future. Different from culture (Rollason 2014:11) or symbol (Castoriadis 1987: 127), imagination is less circumscribed by the established representation, and more flexible in its form and content. Compared to other similar concepts, such as hope (Miyazaki 2004; Miyazaki and Swedberg 2015) or aspiration (Appadurai 2004), imagination is less repetitive and more free. An imagining activity thus brims with possibilizing power, "directing itself to what might be rather than to what must be" (Casey 1976: 231). Imagination can even turn into fantasy if it deviates substantially from the real world (Weiss 2009). Or it can be at least a haven or illusion for people to escape - if only temporarilyfrom their predicaments or marginalization.

Imagination and fantasy have recently been treated in studies on minorities and Han people in China and Taiwan, becoming important concepts to reflect on the nation-state (Mueggler 2001), kinship (Sangren 2013), mobility (Chu 2010), and the reconstitution of contemporary rural or urban places (Huang 2016a; A. Lee 2015). Their theoretical tendencies are varied, ranging over works by Castoriadis (1987), Munn (1986), Taylor (2004), and scholars of psychoanalysis. This book, 
being concerned with social imaginary, is closer to and inspired by Mueggler and Huang. For example, it is unsurprising that the state is omnipresent in southwest China, but Mueggler's description of the potent use of rituals (instead of political institutions or policies) by the Lòlop'ò people there to envision the power of the state is insightful (2001: 198). I will show how people, not only in the southwestern mountains, but also on islands in the southeastern seas have configured new modes of action to divert or deflect the grasp of the state. This book also draws on Huang's (2016: 23) exploration of how social imaginings are invented to create new sociality in contemporary Taiwan. Equally, this book shares with Chu (2010: 5) an interest in probing the aspiring subjects, their desires, and their spatial-temporal extensions of transnational mobility. However, I focus more granularly on the imagining subjects themselves, interrogating their subjectification processes and varied uses of mediating technologies to constitute new social imaginaries. I believe these perspectives can bring us closer to the people in this society who always confront instability and face an uncertain future. Above all it is their in-betweenness and rootlessness which echo most insistently our own precarious state of living in the contemporary world, while their curiosity in exploring - and resourcefulness in forgingnew paths and futures for themselves brings us hope.

\section{The Ethnographic Setting}

From north to south, the Matsu archipelago comprises Dongyin, Xiyin, Beigan, Nangan, Xiju and Dongju, among other islands. They run to the northeast of Fujian province, close to the estuary of the Min River and only sixteen nautical miles from Fuzhou (Map 0.1). Because the islands are mountainous and narrow, they were initially used mainly as a temporary waypoint for fishermen from Changle and Lianjiang. Later, dwellings were built around the inlets, until villages eventually formed along the hillsides. Fishermen sold their catch along the coast of Fujian, trading for necessities to bring back (J. Lin 1991). Each island, whether in terms of economy or other social factors, was therefore closely tied to the Fuzhou region. Their customs, cultures, and languages all bore resemblance to those of eastern Fujian.

In the past, each island had its own name (or even multiple names) that spoke to its own special characteristics. For example, the southernmost 


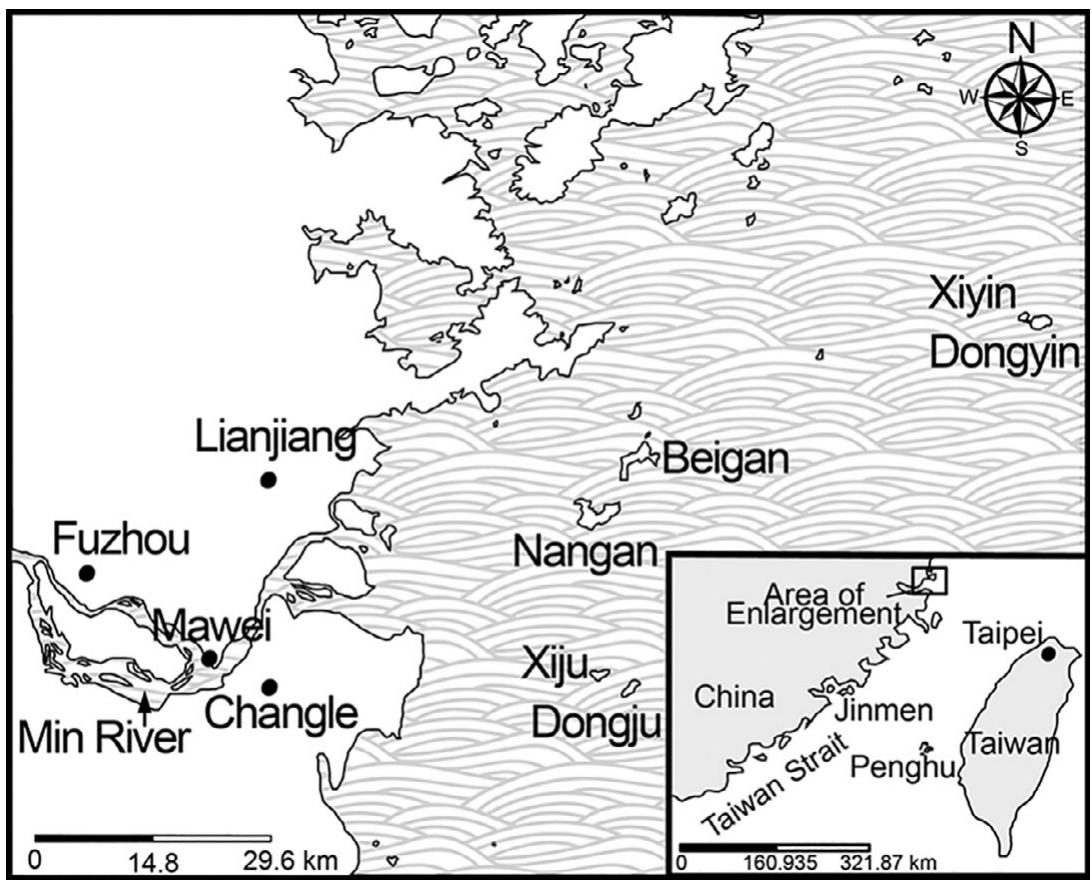

Map 0.1 Matsu's position between Fujian and Taiwan

group of islands was called White Dog (F. pa ing), because on misty days, from afar they looked like a crouching dog. The islands were divided east and west, and so became East Dog and West Dog, or lower and upper, so Lower Sands and Upper Sands. The two islands in the middle of the archipelago, Nangan and Beigan, were known as Matsu after the temple to the Goddess Mazu built there (Y. Yang 2014: 143). Located far to the north were Dongyin and Xiyin, whose interaction with the other four islands was fairly limited.

Beginning in the twelfth century, the islands gradually began to be mentioned in local gazetteers. As they were located well out to sea, descriptions were sparse, and details remained unknown. Cultivation of the islands was frequently prohibited or suppressed by adjacent coastal defense authorities, and so they oscillated between being temporary waypoints and abandoned wasteland. This lasted until 1790, when the Qianlong Emperor 
decreed cultivation in the southeast islands legal, and people from the coast of Fujian gradually began to make their way there. The present villages were mostly formed by the end of the nineteenth century. The people, however, continued to move freely between the islands and the mainland, and were not long-term residents of the archipelago.

In 1949, the armed forces of the Nationalist Government withdrew to the islands off the southeast coast of the mainland after suffering a series of losses to the Communists. The military arrived in Nangan and established the "Matsu Garrison Command Post" (Matsu shoubeiqu zhihuibu) and the "Matsu Administrative Office" (Matsu xingzheng gongshu) in order to administer Matsu's six islands and the four islands to the north. As those northern islands fell successively under communist control, the Nationalist Government ended up with a total of six islands, which later came to be known generally as "Matsu." The six islands were administratively named Lianjiang county, a name borrowed by the army from the nearby coastal mainland. The objective was to demonstrate that the Republic of China (ROC) still had control over mainland territory in addition to holding Taiwan. Even today, there is a "Lianjiang county" on both sides of the Taiwan Strait. In short, these islands were united by virtue of historical happenstance, as the result of the confrontation between the People's Republic of China (PRC) and the ROC military forces. This book applies the most commonly used term, "Matsu," to refer to these islands.

The arrival of the military utterly transformed life on the islands. The conflict between the PRC and the ROC turned Matsu into a frontline and severed its previously close contact with and reliance on the mainland. In an instant, the islanders were stranded at sea. With 114 nautical miles and more than a ten-hour marine voyage from Taiwan, Matsu was positioned as the sole island border in the distant north of Taiwan. In 1956, the Nationalist Government implemented a system of warzone administration in Matsu, and the islands fell completely under military control. Not only were ordinary Taiwanese prohibited from visiting the islands, but islanders could no longer come and go at will, and so Matsu became a military zone cut off from the rest of the world. Only with the democratization movement in Taiwan in the 1980s, when Matsu people also participated in demanding change, did military rule over the islands finally fade into the history books. However, although martial law has 
long since been lifted, even today Matsu remains vague in the minds of many Taiwanese, still muddied with past images of military rule and faraway frontiers.

Becoming a frontline brought tremendous restrictions to the lives of the fishermen of Matsu. The fishing economy took a beating and went into a steep decline. When Taiwan embarked on a path of industrialization in the 1970s and needed a vast new workforce, large numbers of Matsu people moved there to find employment. Many of them ended up in the industrial zone in Taoyuan, and in particular today's Bade City. There is still a "Matsu Street" there, with venders selling local products from Matsu. Most of the people who remained in Matsu engaged in some kind of commerce, selling products to the military in what is commonly known as " $\mathrm{G}$. I. Joe business" (a'bing'ge shengyi). After martial law was lifted in 1992, the soldiers gradually left, and demand for these products and services waned. As relations improved between Taiwan and China, the two sides established the "Three Great Links" (da santong) in 2008, opening up bilateral post, trade, and transportation. Stripped of its military usefulness, Matsu today is facing the difficult question of where to go from here.

\section{Ox Horn in Nangan Island}

Matsu's population peaked in 1970 at 17,000 people. The decline of the fishing economy and subsequent emigration brought that number to around 5,500 by 1990 . At present, there are more than 10,000 people registered in Matsu, but long-term residents number only between 5,000-6,000. I have conducted interviews with people across all of the islands, but my in-depth fieldwork was carried out in Ox Horn (F. ngu oyh) in Nangan. ${ }^{4}$ This village is located in northeastern Nangan (Map 0.2) and was the island's primary village before 1960. This was mainly because the village faces the waters shared with Beigan, and the tides in both directions are quite rapid, making it an excellent place for fishermen to set up their nets (J. Liu 1996a). Indeed, many fishermen settled there in order to be close to their fishing grounds. The Fujian provincial government set up a salt warehouse there at the beginning of the twentieth century so that the fishermen could easily salt their catch. 


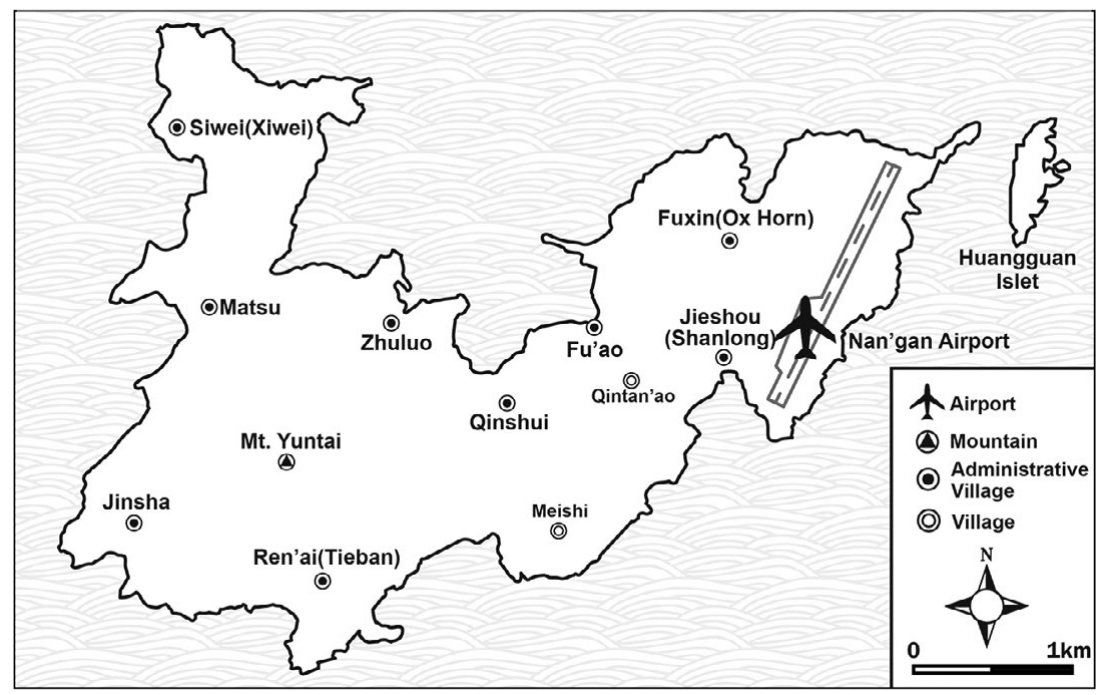

Map 0.2 Nangan Island

After the Nationalist Government took control of the islands, the village became politically important, as the warzone administration established its offices (later to become the Lianjiang county government), stationed security and law enforcement officers, and built a hospital and other facilities there. Yet since land in Ox Horn was limited, there were not sufficient opportunities for development, and the government organizations successively left the village to find larger sites on which they could expand. As the fishing economy floundered and waves of locals left for Taiwan, the village fell into decline. The history of Ox Horn demonstrates several important historical changes that Matsu as a whole underwent, as well as the issues the archipelago is currently facing, which is why I chose it as the main site for my field research. Another important site is Ox Horn's neighboring village, Shanlong (Jieshou), where the county government seat and the only marketplace on Nangan Island are located. Much of the information about the fishing economy in this book was collected in Dongyin, the northernmost island close to many rich fishing grounds. In the past, when the fishing season approached, many Matsu locals would gather there for large-scale fishing, and so 
many residents there were highly experienced fishermen and often excellent storytellers. I also conducted interviews in Taoyuan, Taiwan, and in some cities in mainland China where I followed my informants during fieldwork.

The place names of Nangan mentioned in this book are all displayed in Map 0.2. The islands and villages of Matsu often have two different names, one the locals use and one decreed by the military. If the army felt that the name of a place sounded "uncouth," they gave it a new name. The new ones generally connote military or governmental ideology; for example, Baiquan (White Dog) was renamed as Juguang (an allusion to a historical allegory about recovering national territory), $\mathrm{Ox}$ Horn as Fuxing (referring to the rejuvenation of China), Shanlong (a small piece of land by the mountains) as Jieshou (a reference to celebrating Chiang Kai-shek's birthday), Tieban (a plank of iron) as Ren'ai (meaning 'love for humanity,' a Confucian virtue), and so on. Locals became accustomed to the new names and often used both interchangeably. Because the names of the islands and their main Goddess are homophonic, I have for clarity decided to use "Matsu" for the name of the islands and "Mazu" for the name of the Goddess.

\section{Jinmen, Matsu, and Beyond}

Matsu was not the only archipelago on the military frontline. Jinmen, to its south, was the site of several important battles. It is better known generally, and also has been the subject of more scholarship. A range of research has been conducted by a succession of scholars, including on its kinship, architecture, and migration process (Chiang 2009, 2011), as well as on its economy and religion (Chi 2009, 2015). In recent years the historian Michael Szonyi has made very important contributions to the study of Jinmen's social history. His Cold War Island (2008) takes the perspective of geopolitics to analyze how the war between the PRC and the ROC and the US-Soviet Cold War had a sudden and profound effect on the local society. He explains how militarization (Enloe 2000; Lutz 2004) penetrated the families, religion, and economy: military values and interests, together with various modernization projects, turned frontline Jinmen into a "militarized utopian modernity" (Szonyi 2008: 6). 
Szonyi's book offers an important basis for understanding Matsu's history. His analytic point-placing Jinmen in the geopolitical framework of the Cold War-gives us a much wider lens through which to examine local society. My book benefits greatly from it. As an anthropologist, however, I take a different approach: my research and fieldwork are focused on the islanders' experiences of this historical period from their lived worlds. Those who lived through military rule do not easily reveal their inner feelings and thoughts about that time. But through their living experiences - spatial movements, economic practices, and leisure activities-we can come closer to their lives during the military period.

This book also takes the different histories and ecologies of Matsu and Jinmen into consideration to explore how the same system of rules applied in two different places can give rise to alternate worlds and views. Put differently, I am concerned with the ways that local culture and society articulate with the military. For example, unlike Jinmen with its longstanding history of cultivation and well-developed society, Matsu in its early stages was merely a temporary stopover for fishermen. The rudimentary and very limited development on the islands meant that locals had conflicted feelings about military rule and its effects, since along with the strictures of authoritarian rule, the army also brought large-scale construction projects and widespread elementary education. These were advantages that the people living on these small islands had never experienced before. As described above, Matsu was never selfsufficient, and it relied on the mainland for supplies and education. Military rule brought oppression, but it also created new opportunities, engendering, if not a purely positive attitude toward the army, at least a more ambivalent love-hate relationship with it; this is very different from Jinmen.

This rather different picture of the military world in Matsu has to further take account of the culture of fishing. Consider, for example, gender relations: The social situations of women in Matsu during the fishing era, under the warzone period, and in the present day are markedly different from those of women in Jinmen. During the height of the fishing economy, men went out to sea to fish and make money, while women stayed behind and took care of the household. In a society in which marine accidents were common and residence was temporary, 
women had to take on the role of maintaining the household and often became the center of the house. Despite this, women had no actual income, and their overall status remained low in a patrilineal society. When the army arrived and a military economy was established, however, women had new opportunities to make money. Their economic contributions to the household often exceeded what their husbands could earn from fishing or doing low-level government work. Unlike the women in Jinmen, new economic practices during the military era transformed the women of Matsu, especially those who engaged in petty business with soldiers. They left the isolation of the house and formed their own sister teams; they began to participate in public affairs and gradually gained a space outside of the patrilineal society.

Another quality of the fishing society which characterized this period was its gambling culture. Gambling was a common pastime for islanders as they waited for the tide to turn, and it was an important way of cultivating bravery and daring in fishermen who faced unpredictable situations. It is in the practice of gambling that we most clearly see the Matsu people's characteristic willingness to take chances and wager against fortune. When the army took over, gambling was strictly banned, possibly to prevent unauthorized groups of people from gathering. Nevertheless, it persisted even as the military implemented increasingly harsh punishments. Various kinds of gaming became ever more widespread, reaching people in every walk of life in coordination with their new social and economic dynamics. This book will further explore how these gambling practices became an emotional release and a kind of imaginative evasion by which the islanders could endure, play with, and deflect the oppressive might of military power.

When martial law was finally abolished, all kinds of information channels were opened, and new media technology made its way into Matsu. Owing to its location at the farthest northern border of Taiwan, its scattered islands, and inconvenient transport links, interactions between the islands themselves had never been easy. The unique geography of the archipelago gave the new media technology a chance to thrive, and Matsu Online, with its instantaneous newsfeed, quickly swept across the islands. Its focused reporting on Matsu further fostered a new kind of emotional connection between the islands that the army had never encouraged, 
instead emphasizing the self-sustainability of each island so as to be able to fight independently in a war. Internet technology in Matsu gave rise to a new sense of place (Miller and Horst 2012: 27). This process was completely different from Jinmen where a single big island dominates, and which is also much better connected by air to Taiwan. Although a similar website, “Good Morning, Kinmen" (Zao'an finmen), followed the style of Matsu Online, it was never as influential. The peculiar effervescence of cultural practices and media technology in contemporary Matsu shows that it is a highly imaginative space which can no longer be understood only through a Cold War Framework. Imagination is the key to this frontier society.

\section{Book Outline}

The book is divided into three parts - namely, the history of the Matsu archipelago, new technologies of the imagination, and fantasias of the future. These cover the span from the early settlement of the islands to the period of military rule and lead up to the current era. Part I is the historical portion, with Chapter 1 introducing pre-1949 Matsu as a stateless and fragmented society. Lying at the frontier of the state, the islanders had strong links to the mainland. Chapter 2 discusses the complete transformation of the islands upon the establishment of the warzone administration in Matsu. This chapter focuses on the reformation of landscape and on space; that is, the ubiquity of military institutions, the imposed isolation of the islands, and the suffering involved in difficult sea journeys to Taiwan.

Chapter 3 analyzes the appearance of new social categories and the changes in gender relations in wartime Matsu. I show that the military's strictures on the fishing economy brought about its eventual collapse, while its guaranteed admission program gave rise to a new category of public servants and teachers who returned from Taiwan to work in return for free education received there. Those who remained on the islands engaged in petty business, catering to the needs of the army. The status of women was notably elevated as they began to have greater opportunities to earn money. The final chapter in Part I, Chapter 4, examines gambling practices within the context of the islands' fishing culture and the socioeconomic transformation in the military period to demonstrate 
that what started as a leisure activity of fishermen eventually became a pervasive daily pastime for Matsu residents from every walk of life.

Following the dismantling of the military government in 1992, new media technology arrived in Matsu. Part II explores how this technology enabled the creation of a new imaginary of Matsu. Chapter 5 discusses how the website Matsu Online quickly became an essential aspect of island life, with its finger on the pulse of society. Simultaneously, it surmounted the limitations of the archipelago's geography, connecting Matsu, Taiwan, and China together into a "new online community." Chapter 6 narrows the focus to individuals and explores how the advent of Matsu Online opened up possibilities for the development of individual imaginations. This chapter takes the wildly popular Matsu Online serial The Wartime Childhood of Leimengdi as its main case study to explore how online writing can become a process of subjectification by which individuals and social relationships are renewed. It lays important groundwork for the final section of the book, which discusses the transition from individual imaginations to social imaginary.

Part III, focusing on island fantasias of the future, addresses the different imaginaries towards which the Matsu subjects are aspiring. Chapter 7 takes three women born in the period $1950-80$ as examples with which to analyze the rise of a new self-consciousness among women and the changing meanings of marriage and family. Women in presentday Matsu are still struggling to balance traditional motherhood and their careers. Their difficulties importantly reflect the challenges that contemporary Matsu society is grappling with.

Chapters 8 and 9 discuss how the educated middle-aged generation who returned from Taiwan deployed rituals, myths, and religious material practices to connect Matsu to a larger world. Chapter 8 looks at how Cao Yixiong - a member of the county legislature who had worked in Taiwan-introduced the Taiwanese idea of a "community building project" to turn Matsu into an "Eastern Fujian Culture Village," and later constructed a temple with the support of local residents. I show that the materializing process of temple building became a medium in which individual imaginations could negotiate and spread out into a social imaginary. Chapter 9 examines pilgrimages, the invented myth of "Goddess Mazu in Matsu," and the construction of a giant statue of 
the Goddess. I point out that these innovations in rituals, myths, and material practices are a series of imaginaries which attempt to rescale Matsu within a greater geopolitical framework in order to forge a bridge between the two contentious sides of the Strait.

The final chapter discusses the attempts of the county commissioner, Yang Shuiseng, to bring to Matsu an American gaming capitalist's global project, an "Asian Mediterranean." The vehement debates this project elicited—leading up to a public referendum — demonstrate that contemporary Matsu subjects have diverse visions of the future. This chapter pays particular attention to the young generation that grew up after the military period, whose understanding of Matsu and expectation of the future are entirely different from those of elderly fishermen or middle-aged generations. Finding an amicable resolution for these contending views of the future will present a challenge to the islands in the days ahead.

In the conclusion, I argue that imagining subjects are a vital basis for the social imaginary. Despite the fact that the projects "Eastern Fujian Culture Village," "Goddess Mazu in Matsu," and "Asian Mediterranean" seemingly all came to naught, the imagining subjects still remain potent and continue to pursue further dreams. The case of Matsu, an isolated archipelago in the Taiwan Strait, is thus not an exception. Its liminal existence epitomizes the experiences of Taiwan (Weller 2000) and of many other places which are caught between much bigger powers.

The Matsu archipelago, in many ways, also reminds us of the Trobriand islands. Though they have in common their minute size and relative geographical isolation, it is the Trobrianders' imaginative capacity and adventurous explorations of their imaginings that truly capture our attention. We are already familiar with the Trobrianders in the Pacific; we are still getting to know the Matsu people's daring adventures in the mercurial contemporary world. 
